\title{
ダイナミックキャッチングにおける球状物体の状態遷移
}

\author{
東 森 充* 城 野 淳* 金子 真*
}

\section{State Transition of a Sphere Object on Dynamic Catching}

Mitsuru Higashimori*, Atsushi Jono* and Makoto Kaneko*

\begin{abstract}
This paper discusses the behavior of a sphere object sandwiched by a parallel gripper, while catching. Through the analysis, we found an interesting behaviors of the sphere, where the object never stops under $\boldsymbol{v}^{\mathrm{T}} \boldsymbol{\omega} \neq 0$ and the object with $\boldsymbol{v}^{\mathrm{T}} \boldsymbol{\omega} \neq 0$ first results in $\boldsymbol{v}^{\mathrm{T}} \boldsymbol{\omega}=0$ before starting a rolling motion at one side of contact point. These behaviors are supported by three theorems. We also show some simulation for confirming the analytical results.
\end{abstract}

Key Words: Dynamic Catching, High Speed Capturing, Dynamic Friction Closure, Sphere Object

\section{1. は じめに}

従来のロボットによる対象物の把握や操り [1]〜 [7] では, ほ とんどの場合，準静定（静的なバランスの連続変化）の仮定が 満たされる程度のゆっくりした運動が取り扱われていた。三平 ら [12] は，2 枚の板で剛球を挟み込み, 球の転がりを用いて任 意の位置に球を移動させる問題を取り扱っている. Mason and Lynch [13] は，ダイナミクスを考虑した運動学的拘束を使って 対象物を操る概念として，Dynamic Closure を定義した。ま た, 動体の捕獲に関する研究として, Allen ら [14], Hong [15], Namiki ら [16] [17] は, ビジョンシステムを使って動体の動き を認識し，その捕獲に成功している。ただし,これらの従来研 究では, 動体の速度は遅い. さらに, 三次元高速動体を捕獲す る際のハンド内での動体の振る舞いについて議論された研究は ない.

一方, Fig. 1 のように高速で運動する物体を把握する場合 [8]〜 [10]，ロボットハンドと物体間の滑りゼロで物体を停止させるこ とは不可能で，必ず両者の間で滑りが発生する。そのため, 動 体を確実に把握するためには，ロボットハンドのサイズを検討 する上で，ハンド内における動体の振る舞いを考察する必要が ある. Kanekoら [11] は,このような動体捕獲に関して，動体 をハンドで捕獲する際のクーロン摩擦に基づく滑り量を指標と する Dynamic Friction Closure という概念を提案した。彼等 らは，“動体をグリッパ内で完全に静止させることができるとき Dynamic Friction Closure が成立している”と定義し, 円柱物 体に対して運動エネルギーと滑り量との関係について興味深い考 察を行っているが, 問題設定は二次元に限定されていた，本研究

原稿受付 2003 年 3 月 13 日

*広島大学大学院工学研究科

${ }^{*}$ Graduate School of Engineering, Hiroshima University

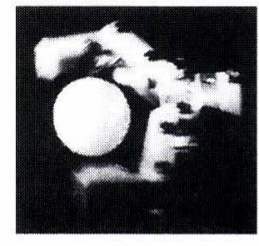

(a)

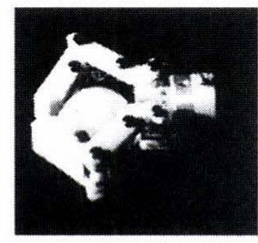

(b)
Fig. 1 An example of high speed capturing motion

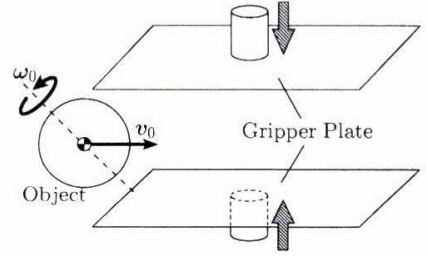

(a) Approach phase

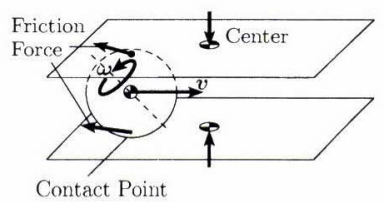

(c) Initial contact phase

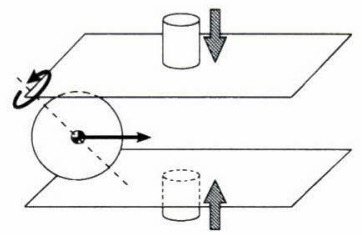

(b) Approach phase

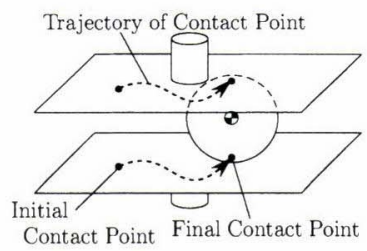

(d) Final contact phase
Fig. 2 Conceptual image of dynamic catching

では, 文献 [11] の研究を内包するような形で三次元に拡張する ことを試みる。ここでは，単純な動体把握モデルとして，Fig. 2 のような球状動体の捕獲問題を考える.Fig. 2 (a)のように, 動 体は初期条件として並進速度 $\boldsymbol{v}_{0}$, 角速度 $\boldsymbol{\omega}_{0}$ 有しているもの とし，把握するロボット側として 2 枚の平行なグリッパを想定 
する.動体捕獲を行う際に，グリッパと動体の間には三つの過程 が存在する。まず，グリッパの動体へのアプローチ（Fig. 2 (a) (b)), 次にグリッパと動体との最初の接触 (Fig. 2 (c)), 最後 に動体の停止に伴う最後の接触（Fig. $2(\mathrm{~d})$ ) である.グリッパ が動体に接触したとき（Fig. $2(\mathrm{c})$ ), 動体に接触力が働き，グ リッパ内を動体が滑りまたは転がりながら移動することになる. Fig. 2 (d) には, 動体がグリッパに最初に接触してから停止する までの軌跡の一例を描いている。この軌跡は, 動体が元々持つ 初期速度と角速度の組み合わせにより決定されるものである.

本論文では, 初期速度 $\left(\boldsymbol{v}_{0}, \boldsymbol{\omega}_{0}\right)$ でグリッパに進入した球状物 体が静止するまでにどのような接触力をグリッパから受けるか, さらに，その接触力によって運動方向がどのように変化するか について考察し, 安定平衡状態と不安定平衡状態の存在を明ら かにする，さらに，任意の初期状態でグリッパ内に進入してく る球は, 必ず $\boldsymbol{v}^{\mathrm{T}} \boldsymbol{\omega}=0$ になるまで滑り続け, $\boldsymbol{v}^{\mathrm{T}} \boldsymbol{\omega}=0$ になっ た後に片側の接触点にて転がりが発生し，そのまま $\boldsymbol{v}^{\mathrm{T}} \boldsymbol{\omega}=0$ を保った状態で静止するという興味深い点を明らかにする. 本 研究では, これに関連する性質を三つの定理としてまとめ, 最 後にシミュレーションによって球の振る舞いについて確認する.

\section{2. モ デル化}

\section{1 仮定}

本研究で扱うモデルを Fig. 3 に示す. 議論を簡単にするため 以下のような仮定を設ける。

仮定 $1: 2$ 枚の平行なグリッパを考える.

仮定 $2 ：$ グリッパと対象物との接触は, 点接触とする.

仮定 3: グリッパは, 対象物に対し, 一定の力を加える.

仮定 4: 摩擦はクーロン摩擦のみを考え, 静摩擦と動摩擦は 区別しない。

仮定 5：対象物は球形状とし, 一様な質量分布を持つ剛体と する.

仮定 6 ：対象物は, 初期並進速度 $\boldsymbol{v}_{0}$ と単一軸周りで表現さ れる初期角速度 $\omega_{0}$ を持ち,グリッパ内に進入する まで両速度は変化しない。

仮定 7 ：グリッパ面の法線方向は $\boldsymbol{v}_{0} \times \boldsymbol{\omega}_{0}$ とする.ただし， $\boldsymbol{v}_{0} \times \boldsymbol{\omega}_{0}=0$ の場合， $\boldsymbol{v}_{0}$ と直交するような方向から 任意に与えるものとする。

仮定 8：グリッパと対象物の衝突時のエネルギー損失はない ものとする.

仮定 9 ：重力の影響は考えない.

仮定 2 より，グリッパと対象物との接触点を結んだ直線回りの 回転運動は停止させることができない。ここでは, 最終的に対

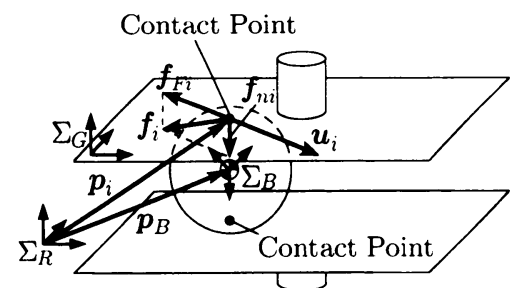

Fig. 3 Contact model
象物のすべての速度成分がゼロになるようにするために，グリッ パの初期姿勢を仮定 7 のように置いた。

\section{2 運動方程式}

Fig. 3 のように, $\Sigma_{R}, \Sigma_{G}, \Sigma_{B}$ をそれぞれ, 基準座標系, グリ ッパに固定された座標系 (グリッバ面の法線方向を $z_{G}$ 軸とする), 対象物の重心位置に固定された座標系とし, $\boldsymbol{p}_{B}, \boldsymbol{p}_{i}(i=1,2)$ をそれぞれ $\Sigma_{R}$ から見た対象物の重心への位置べクトル，各接 触点への位置べクトルとする。このとき, 対象物の重心から各 接触点への位置ベクトルは, $\boldsymbol{r}_{i}:=\boldsymbol{p}_{i}-\boldsymbol{p}_{B}$ と表すことができ る. また, 対象物の並進速度べクトル $\boldsymbol{v}\left(=\dot{\boldsymbol{p}}_{B}\right)$, 角速度べクト ル $\boldsymbol{\omega}$ を用いると, 各接触点の並准速度は $\boldsymbol{u}_{i}=\boldsymbol{v}+\boldsymbol{\omega} \times \boldsymbol{r}_{i}$ と なる．接触点に加わる摩擦力 $\boldsymbol{f}_{F i}$ は， $\boldsymbol{u}_{i}$ の逆向きに発生する ことを考慮し，

$$
\boldsymbol{f}_{F i}=-\mu\left\|\boldsymbol{f}_{n i}\right\| \frac{\boldsymbol{v}+\boldsymbol{\omega} \times \boldsymbol{r}_{i}}{\left\|\boldsymbol{v}+\boldsymbol{\omega} \times \boldsymbol{r}_{i}\right\|}
$$

となる。ただし， $\mu$ は摩擦係数， $\boldsymbol{f}_{n i}$ は対象物がグリッパから 受ける垂直抗力であり, 仮定 3 より一定である。これより, 各 接触点で滑りが起こっている場合, 接触力は以下のようになる.

$$
\begin{aligned}
\boldsymbol{f}_{i} & =\boldsymbol{f}_{F i}+\boldsymbol{f}_{n i} \\
& =-\mu\left\|\boldsymbol{f}_{n i}\right\| \frac{\boldsymbol{v}-\boldsymbol{\omega} \times \boldsymbol{r}_{i}}{\left\|\boldsymbol{v}-\boldsymbol{\omega} \times \boldsymbol{r}_{i}\right\|}+\boldsymbol{f}_{n i}
\end{aligned}
$$

このとき, 対象物の重心に作用する合力 $\boldsymbol{f}_{B}$, 合モーメント $\boldsymbol{n}_{B}$ は, 次のようになる。

$$
\left[\begin{array}{c}
\boldsymbol{f}_{B} \\
\boldsymbol{n}_{B}
\end{array}\right]=\left[\begin{array}{cc}
\boldsymbol{I}_{3} & \boldsymbol{I}_{3} \\
\boldsymbol{r}_{1} \times & \boldsymbol{r}_{2} \times
\end{array}\right]\left[\begin{array}{l}
\boldsymbol{f}_{1} \\
\boldsymbol{f}_{2}
\end{array}\right]
$$

以上より，対象物の運動方程式として，次式を得る。

$$
\left[\begin{array}{cc}
m \boldsymbol{I}_{3} & \mathbf{0} \\
\mathbf{0} & \boldsymbol{H}
\end{array}\right]\left[\begin{array}{c}
\dot{\boldsymbol{v}} \\
\dot{\boldsymbol{\omega}}
\end{array}\right]=\left[\begin{array}{cc}
\boldsymbol{I}_{3} & \boldsymbol{I}_{3} \\
\boldsymbol{r}_{1} \times & \boldsymbol{r}_{2} \times
\end{array}\right]\left[\begin{array}{c}
\boldsymbol{f}_{1} \\
\boldsymbol{f}_{2}
\end{array}\right]
$$

ただし， $m, \boldsymbol{H}$ はそれぞれ対象物の質量，慣性テンソルであ $\eta, \boldsymbol{I}_{3}$ は $3 \times 3$ の単位行列, $\boldsymbol{r}_{i} \times$ は外積と等価な歪対称行列 を表す。

\section{3.グリッパ内での対象物の振る舞い}

一般に，式（4）を解析的に解くことはできない．本章では， グリッパ内における対象物の速度と接触力から, 対象物の振る 舞いを考察する上で重要な基本定理を導出する.

仮定より, 対象物の重心から各接触点への位置ベクトルは, $\boldsymbol{r}_{1}=-\boldsymbol{r}_{2}$, また, 各接触点での垂直抗力は, $\boldsymbol{f}_{n 1}=-\boldsymbol{f}_{n 2}$ と 考えることができる．以下の議論では，必要に応じて，

$$
\begin{gathered}
\boldsymbol{r}_{1}=-\boldsymbol{r}_{2}=\boldsymbol{r} . \\
\boldsymbol{f}_{n 1}=-\boldsymbol{f}_{n 2}=\boldsymbol{f}_{n}
\end{gathered}
$$

とし，共通のベクトル変数 $\boldsymbol{r}, \boldsymbol{f}_{n}$ を用いて表現することにする.

\section{1 接触力と速度の関係}

式（5）を用いて，式（4）を屝開すると,

$$
\begin{aligned}
\dot{\boldsymbol{v}} & =\frac{1}{m}\left(\boldsymbol{f}_{1}+\boldsymbol{f}_{2}\right) \\
\dot{\boldsymbol{\omega}} \times \boldsymbol{r} & =\boldsymbol{H}^{-1} \boldsymbol{A}\left(\boldsymbol{f}_{1}-\boldsymbol{f}_{2}\right)
\end{aligned}
$$




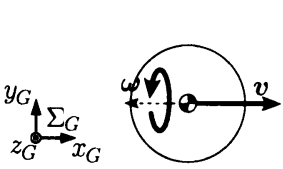

(a)

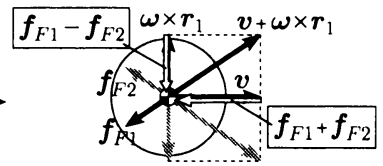

(b)
Fig. 4 Velocity and friction force under $\boldsymbol{v} \times \boldsymbol{\omega}=0$

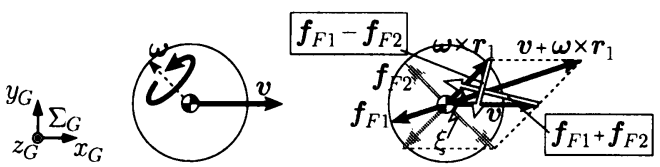

Fig. 5 Velocity and friction force under $\{\boldsymbol{v} \times \boldsymbol{\omega} \neq 0\} \cap\left\{\boldsymbol{v}^{\mathrm{T}} \boldsymbol{\omega} \neq 0\right\}$
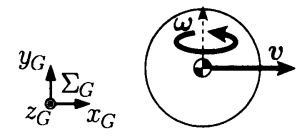

(a)

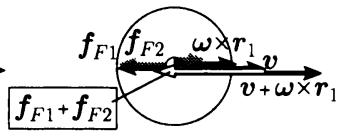

(b)
Fig. 6 Velocity and friction force under $\boldsymbol{v}^{\mathrm{T}} \boldsymbol{\omega}=0$

ただし，

$$
\begin{aligned}
\boldsymbol{r} & =\left[r_{x}, r_{y}, r_{z}\right]^{\mathrm{T}} \\
\boldsymbol{A} & =\left[\begin{array}{ccc}
r_{y}^{2}+r_{z}^{2} & -r_{x} r_{y} & -r_{x} r_{z} \\
-r_{x} r_{y} & r_{x}^{2}+r_{z}^{2} & -r_{y} r_{z} \\
-r_{x} r_{z} & -r_{y} r_{z} & r_{x}^{2}+r_{y}^{2}
\end{array}\right]
\end{aligned}
$$

垂直抗力 $\boldsymbol{f}_{n}$ は対象物の並進㧍よび角速度の変化に影響しない ことを考慮すると. 式 (6)，（7）上り, 摩擦力と速度の関倸に 関して次の性質が得られる.

【性質】 $\boldsymbol{v}, \boldsymbol{\omega} \times \boldsymbol{r}$ の変化は，それぞれ， $\boldsymbol{f}_{F 1}+\boldsymbol{f}_{F 2}, \boldsymbol{f}_{F 1}-$ $\boldsymbol{f}_{F 2}$ によって規定される.

\section{2 速度ベクトルの方向}

並進速度 $\boldsymbol{v}$ の方向と角速度 $\boldsymbol{\omega}$ の回転軸の関係に着目し, Fig. 4 (a)，5 (a)，6 (a) に示すような三つの状態に分けて球の 振る舞いについて考察する。ただし，Fig.4(b)，5(b)，6 (b) は, 摩擦力ベクトルが速度べクトルに与える影響を示したものであ る. なお, Fig. 4〜6の視点は, グリッパ面上方に置かれている.

3. $2.1 \boldsymbol{v} \times \boldsymbol{\omega}=0$

Fig. 4 (a) は, $\boldsymbol{v}$ と $\boldsymbol{\omega}$ が同一直線上に存在する場合，すなわ ち， $\boldsymbol{v} \times \boldsymbol{\omega}=0$ が成立している状態を示している．このとき， 次の定理が成立する.

《定理 1》 $\boldsymbol{v} \times \boldsymbol{\omega}=0$ の場合, 対象物が静止するまで, $\boldsymbol{v} \times \boldsymbol{\omega}=0$ の状態が保持される.

(証明) Fig. 4(b) から分かるように, $\boldsymbol{f}_{F 1}+\boldsymbol{f}_{F 2}, \boldsymbol{f}_{F 1}-\boldsymbol{f}_{F 2}$ はそれぞれ $\boldsymbol{v}, \boldsymbol{\omega} \times \boldsymbol{r}$ に対して逆向きに発生する。したがって， 【性質】より $\boldsymbol{v}, \boldsymbol{\omega}$ の方向は変化しない. よって, $\boldsymbol{v} \times \boldsymbol{\omega}=0$ の状態は保持される。

$3.2 .2 \boldsymbol{v} \times \boldsymbol{\omega} \neq 0$ かつ $\boldsymbol{v}^{\mathrm{T}} \boldsymbol{\omega} \neq 0$

Fig. 5 (a) は, $\boldsymbol{v}$ と $\boldsymbol{\omega}$ の間に $\boldsymbol{v} \times \boldsymbol{\omega} \neq 0$ かつ $\boldsymbol{v}^{\mathrm{T}} \boldsymbol{\omega} \neq 0$ の条 件が成り立っている状態を表している。このとき, 次の定理が 成立する。

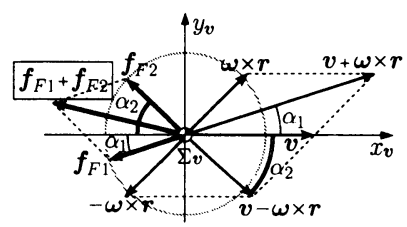

(a)

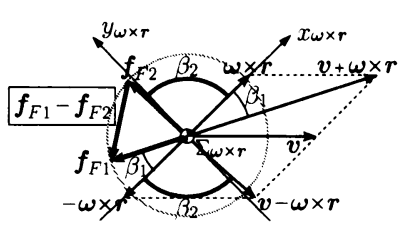

(b)
Fig. 7 Coordinate systems

《定理 2》 $\boldsymbol{v} \times \boldsymbol{\omega} \neq 0$ かつ $\boldsymbol{v}^{\mathrm{T}} \boldsymbol{\omega} \neq 0$ の場合, $\boldsymbol{v}$ と $\boldsymbol{\omega}$ の なす角は漸近的に $\pi / 2$ に収束し, この間, 対象物が静止す ることはない。

（証明） Fig. 5 の接触状態において, $\boldsymbol{v}$ と $\boldsymbol{\omega} \times \boldsymbol{r}$ とのなす角 を $\xi(0<\xi<\pi / 2)$ とする. 速度の条件によっては, $\xi>\pi / 2$ となる場合が存在するが， $-\boldsymbol{\omega} \times \boldsymbol{r}$ を新たに $\boldsymbol{\omega} \times \boldsymbol{r}$ とおいて も一般性は失われないため, $\xi$ の取りうる範囲を $0<\xi<\pi / 2$ と限定して議論すれば十分である. 接触力が $\boldsymbol{v}, \boldsymbol{\omega} \times \boldsymbol{r}$ の方向 に与える影響を調べるため，Fig. 7のような座標系を考える. Fig. 7 (a) は, $\boldsymbol{v}$ の方向および $\boldsymbol{v}$ に垂直な方向にそれぞれ $x_{\boldsymbol{v}}$, $y_{\boldsymbol{v}}$ 軸を持つ座標系 $\Sigma_{\boldsymbol{v}}$, また, Fig. 7 (b) は, $\boldsymbol{\omega} \times \boldsymbol{r}$ の方向お よび $\boldsymbol{\omega} \times \boldsymbol{r}$ に垂直な方向にそれぞれ $x_{\boldsymbol{\omega} \times \boldsymbol{r}}, y_{\boldsymbol{\omega} \times \boldsymbol{r}}$ を持つ座標 系 $\Sigma_{\boldsymbol{\omega} \times \boldsymbol{r}}$ を表している。ここで, 接触力が $\boldsymbol{v}, \boldsymbol{\omega} \times \boldsymbol{r}$ の $y_{\boldsymbol{v}}$ お よび $y_{\boldsymbol{\omega} \times \boldsymbol{r}}$ 方向に及ほす影響について考える。なお, 以下で使 用する “(f)y” などの表記は, ベクトル $\boldsymbol{f}$ の $y$ 方向成分を表す ものとする.

初めに, $\boldsymbol{v}$ の変化について考える.このとき, $\left(\boldsymbol{f}_{F 1}\right)_{y_{\boldsymbol{v}}}<0$, また, $\left(\boldsymbol{f}_{F 2}\right)_{y_{\boldsymbol{v}}}>0$ となり, $\boldsymbol{f}_{F 1}+\boldsymbol{f}_{F 2}$ の $y_{\boldsymbol{v}}$ 方向成分は,

$$
\begin{aligned}
\left(\boldsymbol{f}_{F 1}+\boldsymbol{f}_{F 2}\right)_{y_{\boldsymbol{v}}} & =-\left\|\boldsymbol{f}_{F 1}\right\| \sin \alpha_{1}+\left\|\boldsymbol{f}_{F 2}\right\| \sin \alpha_{2} \\
& =\mu\left\|\boldsymbol{f}_{n}\right\|\left(-\sin \alpha_{1}+\sin \alpha_{2}\right)
\end{aligned}
$$

と表すことができる。ただし，

$$
\begin{aligned}
\sin \alpha_{1} & =\frac{\|(\boldsymbol{v}+\boldsymbol{\omega} \times \boldsymbol{r}) \times \boldsymbol{v}\|}{\|\boldsymbol{v}+\boldsymbol{\omega} \times \boldsymbol{r}\|\|\boldsymbol{v}\|} \\
\sin \alpha_{2} & =\frac{\|(\boldsymbol{v}-\boldsymbol{\omega} \times \boldsymbol{r}) \times \boldsymbol{v}\|}{\|\boldsymbol{v}-\boldsymbol{\omega} \times \boldsymbol{r}\|\|\boldsymbol{v}\|}
\end{aligned}
$$

ここで，式（9），(10）の右辺分子は，いずれも $\|\boldsymbol{\omega} \times \boldsymbol{r} \times \boldsymbol{v}\|$ であり等しい。また，

$$
\begin{array}{r}
\|\boldsymbol{v}+\boldsymbol{\omega} \times \boldsymbol{r}\|^{2}-\|\boldsymbol{v}-\boldsymbol{\omega} \times \boldsymbol{r}\|^{2} \\
=4\|\boldsymbol{\omega} \times \boldsymbol{r}\|\|\boldsymbol{v}\| \cos \xi
\end{array}
$$

$0<\xi<\pi / 2$ より $\cos \xi>0$ のため, 式（11）から

$$
\|\boldsymbol{v}+\boldsymbol{\omega} \times \boldsymbol{r}\|>\|\boldsymbol{v}-\boldsymbol{\omega} \times \boldsymbol{r}\|
$$

式 (9)，(10)，(12）より， $\sin \alpha_{1}<\sin \alpha_{2}$ となるため, 式 (8) から

$$
\left(\boldsymbol{f}_{F 1}+\boldsymbol{f}_{F 2}\right)_{y_{\boldsymbol{v}}}>0
$$

が常に成立する．したがって，接触力により $\boldsymbol{v}$ は $y_{\boldsymbol{v}}$ 軸の正方 向に摩擦力の影響を受け变化することがいえる. 
次に, $\boldsymbol{\omega} \times \boldsymbol{r}$ の変化について考える。 このとき, $\left(\boldsymbol{f}_{F 1}\right)_{y \boldsymbol{\omega} \times \boldsymbol{r}}>$ $0,\left(\boldsymbol{f}_{F 2}\right)_{y \boldsymbol{\omega} \times \boldsymbol{r}}>0$ であるため,

$$
\begin{aligned}
\left(\boldsymbol{f}_{F 1}-\boldsymbol{f}_{F 2}\right)_{y \boldsymbol{\omega} \times \boldsymbol{r}} & =\left\|\boldsymbol{f}_{F 1}\right\| \sin \beta_{1}-\left\|\boldsymbol{f}_{F 2}\right\| \sin \beta_{2} \\
& =\mu\left\|\boldsymbol{f}_{n}\right\|\left(\sin \beta_{1}-\sin \beta_{2}\right)
\end{aligned}
$$

ただし，

$$
\begin{aligned}
\sin \beta_{1} & =\frac{\|(\boldsymbol{\omega} \times \boldsymbol{r}) \times(\boldsymbol{v}+\boldsymbol{\omega} \times \boldsymbol{r})\|}{\|\boldsymbol{\omega} \times \boldsymbol{r}\|\|\boldsymbol{v}+\boldsymbol{\omega} \times \boldsymbol{r}\|} \\
\sin \beta_{2} & =\frac{\|(-\boldsymbol{\omega} \times \boldsymbol{r}) \times(\boldsymbol{v}-\boldsymbol{\omega} \times \boldsymbol{r})\|}{\|-\boldsymbol{\omega} \times \boldsymbol{r}\|\|\boldsymbol{v}-\boldsymbol{\omega} \times \boldsymbol{r}\|}
\end{aligned}
$$

ここで, 式 (15)，(16）の右辺分子は，いずれも $\|\boldsymbol{\omega} \times \boldsymbol{r} \times \boldsymbol{v}\|$ で あり等しい。よって, 式 (12)，(15)，(16）から $\sin \beta_{1}<\sin \beta_{2}$ となるため, 式（14）から

$$
\left(\boldsymbol{f}_{F 1}-\boldsymbol{f}_{F 2}\right)_{y_{\boldsymbol{\omega} \times \boldsymbol{r}}}<0
$$

となる．したがって，接触力により $\boldsymbol{\omega} \times \boldsymbol{r}$ は， $y_{\boldsymbol{\omega} \times \boldsymbol{r}}$ 軸の負方 向に摩擦力の影響を受け変化する．以上の議論により， $\xi \rightarrow 0$.

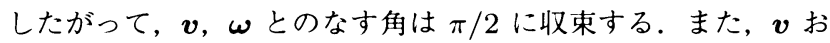
よび $\boldsymbol{\omega} \times \boldsymbol{r}$ の変化する方向は, Fig. $5(\mathrm{~b})$ の $\boldsymbol{f}_{F 1}+\boldsymbol{f}_{F 2}$ および $\boldsymbol{f}_{F 1}-\boldsymbol{f}_{F 2}$ の矢印の方向で表すことができる. 式 (13), (17) より, $\boldsymbol{f}_{F 1}+\boldsymbol{f}_{F 2}$ および $\boldsymbol{f}_{F 1}-\boldsymbol{f}_{F 2}$ はいずれも重心を向くこ とはあり得ない. よって, $\boldsymbol{v} \times \boldsymbol{\omega} \neq 0$ かつ $\boldsymbol{v}^{\mathrm{T}} \boldsymbol{\omega} \neq 0$ のとき， これらの力は $\boldsymbol{v}, \boldsymbol{\omega}$ をゼロに持っていくことはできない. 例えば, Fig. 5 の場合, $\boldsymbol{v}$ の方向は反時計回り, $\boldsymbol{\omega}$ の方向は時 計回りに変化することとなり，次章で述べる $\boldsymbol{v}^{\mathrm{T}} \boldsymbol{\omega}=0$ の状態 に向かう.

\section{$3.2 .3 \boldsymbol{v}^{\mathrm{T}} \boldsymbol{\omega}=0$}

Fig. 6 (a) は, $\boldsymbol{v}$ と $\boldsymbol{\omega}$ が垂直，すなわち $\boldsymbol{v}^{\mathrm{T}} \boldsymbol{\omega}=0$ が成立し ている状態を表している。このとき, 以下の定理が成立する.

《定理 3 》 $\boldsymbol{v}^{\mathrm{T}} \boldsymbol{\omega}=0$ 成立後は, 対象物が静止するまで $\boldsymbol{v}^{\mathrm{T}} \boldsymbol{\omega}=0$ の状態が保持される.

（証明） Fig.6(b) に，摩擦力ベクトルと速度ベクトルの関 係を示す。このとき，各接触点での速度と摩擦力は，すべて同 一直線上に存在し, 摩擦力は対象物の運動方向を変えることな く，静止させようとする方向に働く．したがって， $\boldsymbol{v}^{\mathrm{T}} \boldsymbol{\omega}=0$ が 保持される.

$\boldsymbol{v}^{\mathrm{T}} \boldsymbol{\omega}=0$ が成立している場合, $\boldsymbol{v}$ および $\boldsymbol{\omega}$ から対象物の移 動距離を解析的に得ることが可能である. Fig. 8 は, $\boldsymbol{v}^{\mathrm{T}} \boldsymbol{\omega}=0$ が成立している場合の対象物の速度分布と摩擦力の方向を示し ている。

(i) $\|\boldsymbol{v}\| \geq\|\boldsymbol{\omega} \times \boldsymbol{r}\|$ の場合, 仮定 4 より, Fig. 8 (i) に示すよ うに式（1）で規定される両摩擦力の大きさは等しくいずれも $v$ と逆方向に発生する。この場合, $\|\boldsymbol{v}\|$ のみ減少し, $\|\boldsymbol{\omega}\|$ は保存 される. その後, Fig. 8 (iii) に示すように $\boldsymbol{v}=\boldsymbol{\omega} \times \boldsymbol{r}_{\text {roll }}$ が成 立した後, $\|\boldsymbol{v}\|,\|\boldsymbol{\omega}\|$ が同時に隇り始める。ただし, $\boldsymbol{r}_{\text {roll }}$ は, $\boldsymbol{r}_{1}, \boldsymbol{r}_{2}$ の内, $\boldsymbol{v}=s \boldsymbol{\omega} \times \boldsymbol{r}_{\text {roll }}$ ( $s$ は任意の負の実数 $)$ が成り立 つ側の接触点を表す。このとき, 対象物の移動距離は対象物が 最初に持っていた運動エネルギーから次式の様に表すことがで きる [11].

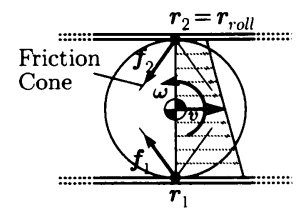

(i) $\|v\| \geq\|\omega \times r\|$

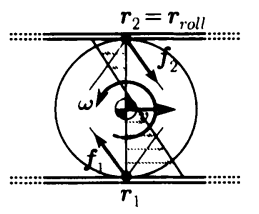

(ii) $\|v\|<\|\omega \times r\|$

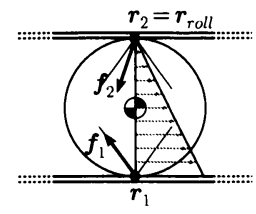

(iii) $\|v\|=\|\omega \times r\|$
Fig. 8 Contact force in a gripper

$$
l_{1}=\frac{\frac{1}{2} m \boldsymbol{v}_{0}^{\mathrm{T}} \boldsymbol{v}_{0}+\frac{1}{2} \boldsymbol{\omega}_{0}^{\mathrm{T}} \boldsymbol{H} \boldsymbol{\omega}_{0}}{2 \mu\left\|\boldsymbol{f}_{n}\right\|}
$$

(ii) $\|\boldsymbol{v}\|<\|\boldsymbol{\omega} \times \boldsymbol{r}\|$ の場合, Fig. 8 (ii) に示すように, (i) と は逆に, 初めに摩擦力は $\|\boldsymbol{\omega}\|$ のみを減少させるよう働き, $\|\boldsymbol{v}\|$ は保存される. その後, Fig. 8 (iii) に示すように $\boldsymbol{v}=\boldsymbol{\omega} \times \boldsymbol{r}_{\text {roll }}$ になった後, $\|\boldsymbol{v}\|$ も減り始める。このとき, 対象物の移動距離 は次式の通りとなる。

$$
\begin{aligned}
& l_{2}=\frac{\frac{1}{2} m \boldsymbol{v}_{0}^{\mathrm{T}} \boldsymbol{v}_{0}+\frac{1}{2} \boldsymbol{\omega}_{0}^{\mathrm{T}} \boldsymbol{H} \boldsymbol{\omega}_{0} P}{2 \mu\left\|\boldsymbol{f}_{n}\right\|} \\
& P=2 \frac{\left(\boldsymbol{\omega}_{0} \times \boldsymbol{r}\right)^{\mathrm{T}} \boldsymbol{v}_{0}-\boldsymbol{v}_{0}^{\mathrm{T}} \boldsymbol{v}_{0}}{\left(\boldsymbol{\omega}_{0} \times \boldsymbol{r}\right)^{\mathrm{T}}\left(\boldsymbol{\omega}_{0} \times \boldsymbol{r}\right)} \quad(0<P \leq 1)
\end{aligned}
$$

式（18）（20）から，初期運動.エネルギー

$$
W=\frac{1}{2} m \boldsymbol{v}_{0}^{\mathrm{T}} \boldsymbol{v}_{0}+\frac{1}{2} \boldsymbol{\omega}_{0}^{\mathrm{T}} \boldsymbol{H} \boldsymbol{\omega}_{0}
$$

が等しい場合でもグリッパ内での対象物の移動距離は異なるこ

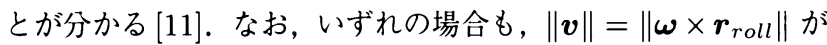
成立した以降は, $\boldsymbol{r}_{\text {roll }}$ 側の接触点では転がり接触が起こること を意味している。

Fig. 8 (iii) は， $\boldsymbol{r}_{2}$ で表される接触点において転がり接触が, $\boldsymbol{r}_{1}$ において滑り接触が起きている際の, 速度分布を表してい る.このとき, $\boldsymbol{r}_{2}$ の接触点について, 次式が成立する.

$$
\boldsymbol{v}=-\boldsymbol{\omega} \times \boldsymbol{r}_{2}
$$

式（22）の両辺を時間微分し, 式（6）に代入することにより,

$$
m \dot{\boldsymbol{\omega}} \times \boldsymbol{r}_{2}=-\boldsymbol{f}_{1}-\boldsymbol{f}_{2}
$$

式 $(5),(7),(23)$ から次式を得る.

$$
\boldsymbol{f}_{2}=(m \boldsymbol{A}+\boldsymbol{H})^{-1}(m \boldsymbol{A}-\boldsymbol{H}) \boldsymbol{f}_{1}
$$

一方, $\boldsymbol{r}_{1}$ 側で転がり接触, $\boldsymbol{r}_{2}$ 側で滑り接触が起こっている場合 においても，同様の関係式が得られる。したがって，滑り側接 触力 $\boldsymbol{f}_{s l i p}$ と転がり側接触力 $\boldsymbol{f}_{r \jmath l l}$ の関係式は次式で表される.

$$
\boldsymbol{f}_{\text {roll }}=(m \boldsymbol{A}+\boldsymbol{H})^{-1}(m \boldsymbol{A}-\boldsymbol{H}) \boldsymbol{f}_{\text {slip }}
$$

$\boldsymbol{f}_{\text {roll }}$ は, 式 (2) の $\boldsymbol{f}_{i}$ で表される接触力が, 接触点の並進速 度方向が反転する際の過渡状態においてバランスした地点での 接触力を表している. なお， $\boldsymbol{f}_{\text {ro:l }}$ は，摩擦円錐内に存在するこ とになる (付録 $\mathrm{B}$ 参照).

\section{3 安定平衡状態と不安定平衡状態}

《定理 1》および《定理 3》により, 対象物が静止する場合, $\boldsymbol{v} \times \boldsymbol{\omega}=0$ あるいは $\boldsymbol{v}^{\mathrm{T}} \boldsymbol{\omega}=0$ のいずれかの条件が成立してい 


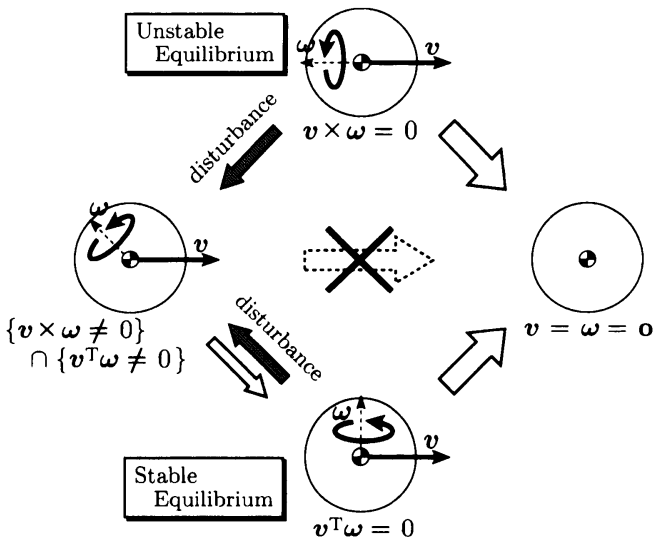

Fig. 9 Transition map
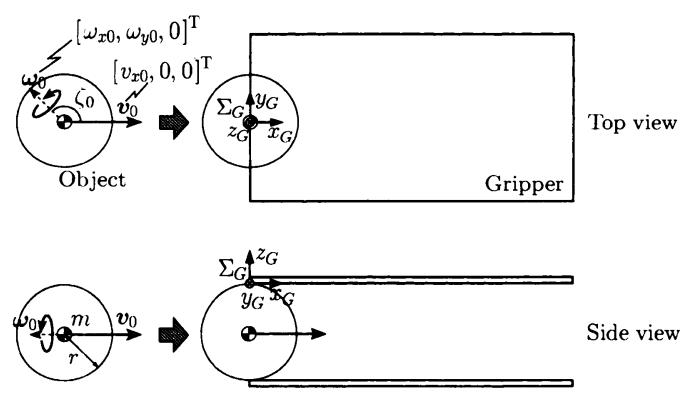

Fig. 10 Simulation model

ることを示した．ただし， $\boldsymbol{v}^{\mathrm{T}} \boldsymbol{\omega}=0$ の状態において外乱の影響 を受けると, $\boldsymbol{v} \times \boldsymbol{\omega} \neq 0$ かつ $\boldsymbol{v}^{\mathrm{T}} \boldsymbol{\omega} \neq 0$ の状態に遷移し, 摩擦力 により元の状態に戻ろうとする復元力が働く(《定理 2》).した がって, $\boldsymbol{v}^{\mathrm{T}} \boldsymbol{\omega}=0$ の状態は, 安定平衡状態と位置付けることが できる，一方， $\boldsymbol{v} \times \boldsymbol{\omega}=0$ の状態では，外乱の影響を受けると 元の状態に戻万うとする復元力は発生しない.したがって,こ の状態は不安定平衡状態と位置付けることができる，Fig. 9 は, 上述の平衡状態および状態遷移の様子を図示したものである.

\section{4. シミュレーション}

シミュレーションでは, ソフトゥェアとして ADAMS（Mechanical Dynamic, Inc.) を使用した. このソフトウェアは数 式モデルを内部に搭載しており, 物体同士の拘束や境界条件を 与えることによって接触力が求まり，動特性を考慮したシミュ レーションが可能となる.

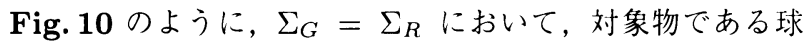
の初期並進速度，初期角速度をそれぞれ $\boldsymbol{v}_{0}=\left[v_{x 0}, 0,0\right]^{\mathrm{T}}$, $\boldsymbol{\omega}_{0}=\left[\omega_{x 0}, \omega_{y 0}, 0\right]^{\mathrm{T}}$, 両者のなす角度を $\zeta_{0}[\mathrm{rad}]$ する. 球とグ リッパは, $\Sigma_{G}$ の原点 $(0,0,0)$ ならびに $(0,0,-2 r)$ で初期接触 を起こし，グリッパ内に進入する。球の半径と質量をそれぞれ $r=0.050[\mathrm{~m}], m=4.085[\mathrm{~kg}]$ とし, 摩擦倸数 $\mu=\tan (\pi / 6)$, グリッパからの垂直抗力 $\left\|\boldsymbol{f}_{n i}\right\|=31.5[\mathrm{~N}]$ とした.

\section{1 速度変化の検証}

Fig. 11 (a) は $\left\|\boldsymbol{v}_{0}\right\|=1.0[\mathrm{~m} / \mathrm{sec}],\left\|\boldsymbol{\omega}_{0}\right\|=0.5[\mathrm{rad} / \mathrm{sec}]$, また, Fig. 11 (b) は $\left\|\boldsymbol{v}_{0}\right\|=0.005[\mathrm{~m} / \mathrm{sec}],\left\|\boldsymbol{\omega}_{0}\right\|=24.7$ $[\mathrm{rad} / \mathrm{sec}]$ のように, 球の初期並進速度と角速度の大きさが極

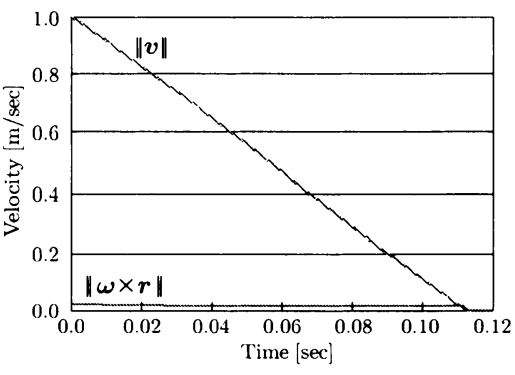

(a) $\|v\| \gg\|\omega \times r\|$

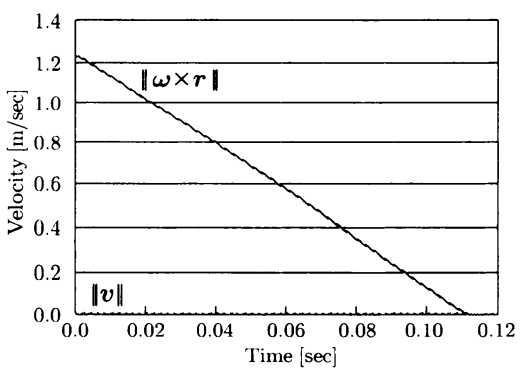

(b) $\|v\| \ll\|\omega \times r\|$

Fig. $11\|v\|$ and $\|\boldsymbol{\omega} \times \boldsymbol{r}\|$

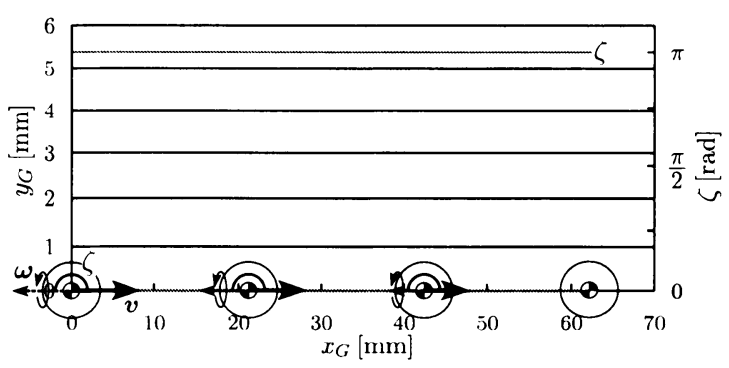

(a) Initial condition: $\boldsymbol{v} \times \boldsymbol{\omega}=0$

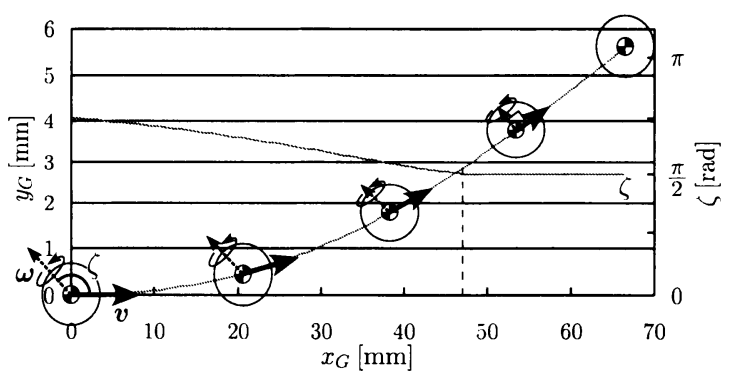

(b) Initial condition: $\{\boldsymbol{v} \times \boldsymbol{\omega} \neq 0\} \cap\left\{\boldsymbol{v}^{\mathrm{T}} \boldsymbol{\omega} \neq 0\right\}$

Fig. 12 The locus of the center of gravity and the angle between $\boldsymbol{v}$ and $\boldsymbol{\omega} \times \boldsymbol{r}$

端に異なる場合における，グリッパに接触してからの球の速度 变化を表している。 Fig. 11 (a), (b) より, 並進速度, 角速度の 内, 初期速度が極端に大きい方は速度変化か激しく，小さい方は ほとんど変化が見られないことが確認できる。こ机は，付録 $\mathrm{A}$ で示す解析結果と一致する。

\section{2 安定平衡状態と不安定平衡状態の確認}

Fig. 12 は, 球の重心位置の軌跡と $v$ と $\boldsymbol{\omega}$ のなす角度 $\zeta[\mathrm{rad}]$ の変化を示している. Fig. 12 (a) は, 初期条件として $\boldsymbol{v} \times \boldsymbol{\omega}=0$ を与えた場合であり，初期速度は $\left\|\boldsymbol{v}_{0}\right\|=1.0[\mathrm{~m} / \mathrm{sec}]$, 


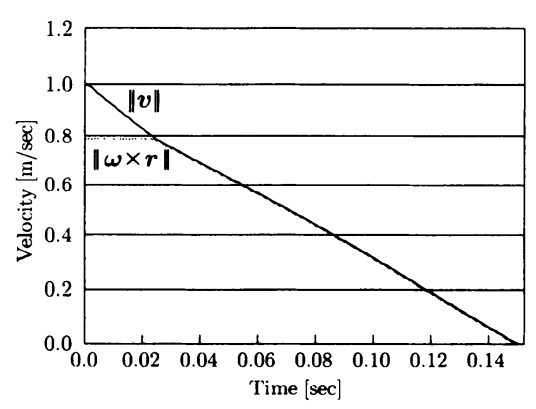

Fig. $13\|\boldsymbol{v}\|$ and $\|\boldsymbol{\omega} \times \boldsymbol{r}\|$ under $\boldsymbol{v}^{\mathrm{T}} \boldsymbol{\omega}=0$



Fig. 14 Moving distance of the object according to $e$

$\left\|\boldsymbol{\omega}_{0}\right\|=15.7[\mathrm{rad} / \mathrm{sec}], \zeta_{0}=\pi[\mathrm{rad}]$ である. Fig. $12(\mathrm{a})$ よ り，球は静止するまで同一方向に移動し続け， $\zeta$ も変化して いないことが分かる.一方，Fig. 12(b) は，初期条件として $\{\boldsymbol{v} \times \boldsymbol{\omega} \neq 0\} \cap\left\{\boldsymbol{v}^{\mathrm{T}} \boldsymbol{\omega} \neq 0\right\}$ を与えた場合であり, 初期速度は $\left\|\boldsymbol{v}_{0}\right\|=1.0[\mathrm{~m} / \mathrm{sec}],\left\|\boldsymbol{\omega}_{0}\right\|=15.7[\mathrm{rad} / \mathrm{sec}], \zeta_{0}=3 / 4 \pi[\mathrm{rad}]$ である. $\zeta$ の変化を見ることで, 軌跡上の原点から初めて $\boldsymbol{v}^{\mathrm{T}} \boldsymbol{\omega}=$ $0(\zeta=\pi / 2[\mathrm{rad}])$ が成立する地点までは, $\boldsymbol{v}$ と $\boldsymbol{\omega}$ が互いに近づ いていき, その後, 静止するまで $\boldsymbol{v}^{\mathrm{T}} \boldsymbol{\omega}=0$ が保持されている ことが分かる.

\section{$4.3 \boldsymbol{v}^{\mathrm{T}} \boldsymbol{\omega}=0$ 成立下での振る舞い}

Fig. 13 に, $\boldsymbol{v}_{0}^{\mathrm{T}} \boldsymbol{\omega}_{0}=0\left(\left\|\boldsymbol{v}_{0}\right\|>\left\|\boldsymbol{\omega}_{0} \times \boldsymbol{r}\right\|\right)$ が成立する条件下

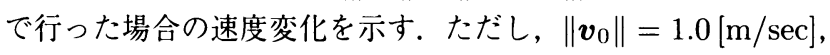
$\left\|\boldsymbol{\omega}_{0}\right\|=15.7[\mathrm{rad} / \mathrm{sec}]$ である. Fig. 13 から $\|\boldsymbol{v}\|>\|\boldsymbol{\omega} \times \boldsymbol{r}\|$ の範囲では, $\|\boldsymbol{v}\|$ のみが減少し, $\|\boldsymbol{\omega} \times \boldsymbol{r}\|$ が保護されているこ とが分かる。このとき, 式（18）功解析的に得られる移動距 離 $l_{1}=69.9[\mathrm{~mm}]$ は, シミュレーションから得られた球の移動 距離 $70.3[\mathrm{~mm}]$ とほほ一致した。

\section{4 移動距離の考察}

Fig. 14 に，初期運動エネルギーを $W=2.55[\mathrm{~J}]$, また， $\zeta_{0}=3 / 4 \pi[\mathrm{rad}]$ に固定した上で, $\left\|\boldsymbol{v}_{0}\right\|,\left\|\boldsymbol{\omega}_{0}\right\|$ を変化させた 場合の球の移動距離を示す. それぞれの点は, 初期運動エネル ギーに対する初期並進エネルギーの割合

$$
e=\frac{\frac{1}{2} m \boldsymbol{v}_{0}^{\mathrm{T}} \boldsymbol{v}_{0}}{\left(\frac{1}{2} m \boldsymbol{v}_{0}^{\mathrm{T}} \boldsymbol{v}_{0}+\frac{1}{2} \boldsymbol{\omega}_{0}^{\mathrm{T}} \boldsymbol{H} \boldsymbol{\omega}_{0}\right)}
$$

に対応している。この結果は，3.2.3 項にあるように，エネル

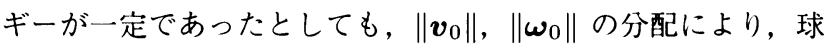
の移動距離が異なることを示している.Fig.15は, 初期速度 を, $\left\|\boldsymbol{v}_{0}\right\|=1.0[\mathrm{~m} / \mathrm{sec}],\left\|\boldsymbol{\omega}_{0}\right\|=15.7[\mathrm{rad} / \mathrm{sec}]$ に固定し， $\zeta_{0}$ を

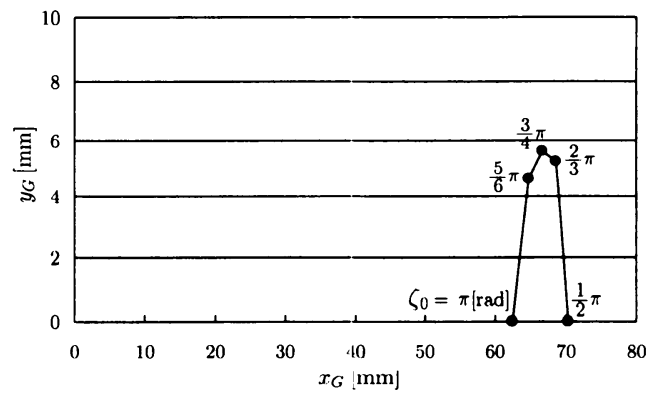

Fig. 15 Moving distance of the object according to the axis of rotation

$\frac{1}{2} \pi, \frac{2}{3} \pi, \frac{3}{4} \pi, \frac{5}{6} \pi, \pi[\mathrm{rad}]$ のよう変化させた場合の球の移動距 離を示している。この場合においても, 初期運動エネルギーは 一定であるが，移動距離に変化を見ることができた。なお，グ リッパとの初期接触点から停止するまでの球の直線移動距離は, $\boldsymbol{v}^{\mathrm{T}} \boldsymbol{\omega}=0$ が成立している場合 $\left(\zeta=\frac{1}{2} \pi[\mathrm{rad}]\right)$ に最長となった.

\section{5. 結論}

本研究では，2 枚の平板グリッパによる球状物体のダイナミッ クキャッチングについて議論した。グリッパ内での対象物の振 る舞いについて考察し，以下のことを示した.

(1) 対象物の並進方向と回転軸方向との関係において, 安定平 衡状態と不安定平衡状態の存在を明らかにした。

（2）対象物の並進方向と回転軸方向のなす角が垂直となってい る場合，対象物の移動距離を解析的に算出できることを示す とともに，初期運動エネルギーが等しい場合でも，並進速度 と角速度の配分によって移動距離が変化することを示した。

（3）シミュレーションにより，（1）（2）に関連した対象物の基 本的振る舞いを確認した。

今後は，本研究で明らかにした定理を積極的に利用した，動体 の操り問題について議論する予定である.

\section{参 考 文 献}

[1] F. Reuleaux: The Kinematics of Machinery. New York: MacMillan, 1876 (Reprint: New York: Dover, 1963).

[2] K. Lakshminarayana: "Mechanics of form closure," ASME, Tech. Rep. 78-DET-32, 1978.

[3] M.S. Ohwovoriole: "An Extension of Screw Theory and its Application to the Automation of Industrial Assemblies,"Ph.D. Thesis, Dept. of Mech. Eng., Stanford Univ., 1980.

[4] V. Ngyuen: "Constructing Force Closure Grasps," The Int. J. of Robotics Research, vol.7, no.3, pp.3-16, 1988.

[5] I.M. Chen and J. W. Burdick: "A Qualitative Test for n-finger Force-Closure Grasps on Planar Objects with Application to Manipulation and Finger Gaits," Proc. of IEEE ICRA, pp.814820, 1993.

[6] J. Ponce, D. Stam and B. Faverjon: "On Computing Twofinger Force-Closure Grasps of Curved 2D Objects," The Int. J. of Robotics Research, vol.12, no.3, pp.263-273, 1993.

[ 7 ] A. Bicchi: "On the Closure Froperties of Robotic Grasping," Int. J. of Robotics Research, vol.14, no.4, pp.319-334, 1995.

[8] M. Kaneko, M. Sawada, T. Tsuji, A. Namiki and M. Ishikawa: "Challenge for the 100G Capturing System," Proc. of JSME Robomech Annual Conf., vol.l, A1-A9, 2001.

[9] M. Kaneko, T. Tsuji and M. Ishikawa: "The Robot that Can Capture a Moving Object in a Blink," In Proc. of 2002 IEEE 
Int. Conf. on Robotics and Automation, pp.3643-3648, 2002.

[10] M. Kaneko, R. Takenaka and M. Ishikawa: "The Capturing Robot with Super High Acceleration," 8th Int. Symp. on Experimental Robotics, Experimental Robotics VIII, 2002.

[11] M. Kaneko, K. Harada and T. Tsuji: "Dynamic Friction Closure," In Proc. of 2002 IEEE Int. Conf. on Robotics and Automation, pp.1584-1589, 2002.

[12] 三平, 水野, 石川, 古賀：“2 枚板に挟まれて運動する剛球の位置制 御”, 日本ロボット学会誌, vol.14, no.8, pp.1237-1242, 1996.

[13] M.T. Mason and K.M. Lynch: "Dynamic Manipulation," Int. Conf. on Intelligent Robots and Systems, pp.152-159, 1993.

[14] P.K. Allen, A. Timocenko, B. Yoshimi and P. Michelman: "Automated Tracking and Grasping of a Moving Object with a Robotic Hand-Eye System," IEEE Trans. on Robotics and Automation, vol.9, no.2, pp.152-165, 1993.

[15] W. Hong: "Robotic Catching and Manipulation Using Active Vision," M.S. Thesis, Department of Mechanical Engineering, MIT, Sep. 1995.

[16] A. Namiki, Y. Nakabo, I. Ishii and M. Ishikawa: "High Speed Grasping Using Visual and Force Feedback," Proc. IEEE Int. Conf. on Robotics and Automation, pp.3195-3200, 1999.

[17] 並木，石井，石川：“高速センサフィードバックに基づく把握行動”, 日本ロボット学会誌, vol.20, no.7, pp.707-716, 2002.

付録 A. $\|\boldsymbol{v}\| \gg\|\boldsymbol{\omega} \times \boldsymbol{r}\|,\|\boldsymbol{v}\| \ll\|\boldsymbol{\omega} \times \boldsymbol{r}\|$ の場合につ いての接触力の考察

式（5）を式（1）に代入すると,

$$
\begin{gathered}
\boldsymbol{f}_{F 1}=-\mu\left\|\boldsymbol{f}_{n}\right\| \frac{\boldsymbol{v}+\boldsymbol{\omega} \times \boldsymbol{r}}{\|\boldsymbol{v}+\boldsymbol{\omega} \times \boldsymbol{r}\|} \\
\boldsymbol{f}_{F 2}=-\mu\left\|\boldsymbol{f}_{n}\right\| \frac{\boldsymbol{v}-\boldsymbol{\omega} \times \boldsymbol{r}}{\|\boldsymbol{v}-\boldsymbol{\omega} \times \boldsymbol{r}\|}
\end{gathered}
$$

(i) $\|\boldsymbol{v}\| \gg\|\boldsymbol{\omega} \times \boldsymbol{r}\|$ のとき

$$
\begin{aligned}
& \boldsymbol{f}_{F 1}+\boldsymbol{f}_{F 2} \simeq-\mu\left\|\boldsymbol{f}_{n}\right\| \frac{2 \boldsymbol{v}}{\|\boldsymbol{v}\|} \\
& \boldsymbol{f}_{F 1}-\boldsymbol{f}_{F 2} \simeq 0
\end{aligned}
$$

摩擦力は, $\boldsymbol{v}$ のみを減速するよう影響し， $\boldsymbol{\omega} \times \boldsymbol{r}$ にはほとんど 影響を与えないことが分かる。

(ii) $\|\boldsymbol{v}\| \ll\|\boldsymbol{\omega} \times \boldsymbol{r}\|$ のとき

$$
\begin{aligned}
& \boldsymbol{f}_{F 1}+\boldsymbol{f}_{F 2} \simeq 0 \\
& \boldsymbol{f}_{F 1}-\boldsymbol{f}_{F 2} \simeq-\mu\left\|\boldsymbol{f}_{n}\right\| \frac{2 \boldsymbol{\omega} \times \boldsymbol{r}}{\|\boldsymbol{\omega} \times \boldsymbol{r}\|}
\end{aligned}
$$

この場合は (i) とは逆に, 摩擦力は, $\boldsymbol{\omega} \times \boldsymbol{r}$ を減速するよう働 くが，vにはほとんど影響を与えないことが分かる。

\section{付録 B． 転がり接触点における接触力}

簡単のため, $\Sigma_{R}=\Sigma_{G}$ として考える.このとき,

$$
\begin{aligned}
\boldsymbol{r} & =\left[0,0, r_{z}\right]^{\mathrm{T}} \\
\boldsymbol{A} & =\left[\begin{array}{ccc}
r_{z}^{2} & 0 & 0 \\
0 & r_{z}^{2} & 0 \\
0 & 0 & 0
\end{array}\right]
\end{aligned}
$$

また，慣性テンソル $\boldsymbol{H}$ を

$$
\boldsymbol{H}=\left[\begin{array}{ccc}
I_{x x} & I_{x y} & I_{x z} \\
I_{y x} & I_{y y} & I_{y z} \\
I_{z x} & I_{z y} & I_{z z}
\end{array}\right]
$$

仮定 5 より，慣性モーメントに関して一般的に次式の関係が成 り立つ.

$$
I_{x x}=I_{y y}=I_{z z}=\frac{2}{5} m r_{z}^{2}
$$

式（B.8）（B.10）を式（25）に代人すると，転がり接触点に おける接触力が次式で与えられる。

$$
\boldsymbol{f}_{\text {roll }}=\left[\begin{array}{ccc}
\frac{3}{7} & 0 & 0 \\
0 & \frac{3}{7} & 0 \\
0 & 0 & -1
\end{array}\right] \boldsymbol{f}_{\text {slip }}
$$

滑り接触点での摩擦力 $f_{s l i p}$ は摩擦円錐に張り付いた状態で発 生する。したがって，式（B.11）より，Fig.8 (iii)に示すよう に, $\boldsymbol{f}_{\text {roll }}$ は $z$ 軸成分に関しては $\boldsymbol{f}_{\text {slip }}$ に対して逆向きかつ摩 擦円錐内に発生することが分かる。

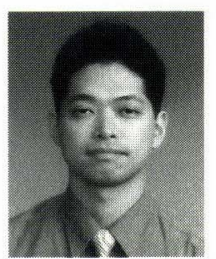

東森 充 (Mitsuru Higashimori)

1974 年 3 月 9 日生. 1998 年広島大学大学院工学 研究科博士課程前期修了。同年株式会社東芝入社. 2002 年 8 月広島大学大学院工学研究科助手, 現在 に至る、ロボットハンド, アクティブセンシングな どの研究に従事. 計測自動制御学会の会員.

(日本ロボット学会正会員)

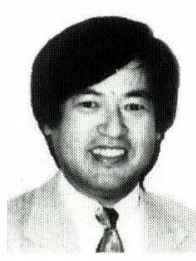

\section{金子 真 (Makoto Kaneko)}

1954 年 1 月 18 日生. 1981 年東京大学工学系研究 科博士課程卒業. 工学博士. 通産省工業技術院機械 技術研究所，九州工業大学助教授を経て，1994 年よ り広島大学教授, アクティブセンシングや把握戦略 の研究に興味を持つ. 日本機械学会奨励賞 (1983), 日本ロボット学会論文賞 (1994), 計測自動制御学会 論文賞（1996，2002），Humboldt Research Award (1997)，IEEE ICRA The Best Manipulation Paper Award (2000), 日本機械学: 会ロボメカ部門功績賞 (2000), IEEE ISATP The Outstanding Paper Award（2001）を受賞.

(日本ロボット学会正会員)

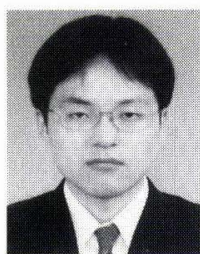

城野 淳 (Atsushi Jono)

1978 年 5 月 17 日生. 2001 年 3 月広島大学工学部 第 2 類 (電気系) 卒業, 同年同大学大学院工学研究 科複雑システム工学専攻博士課程前期入学, 現在に 至る。ロボットハンドによる把握や操りに関する研 究に興味を持つ。 